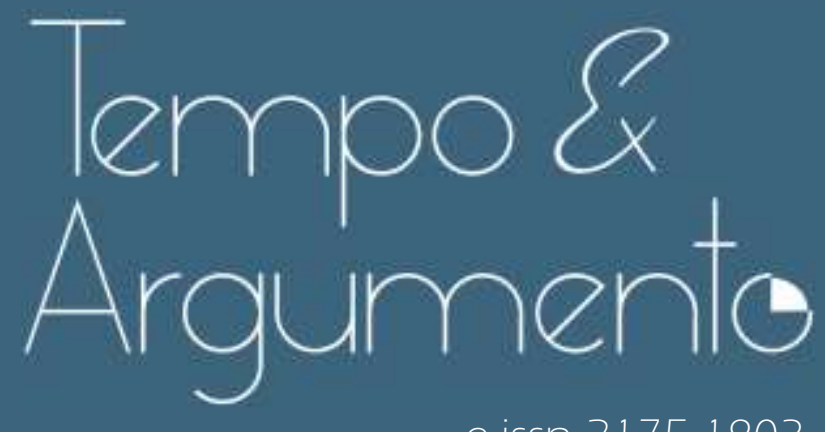

e-issn 2175-1803

\title{
Padre Paulo Ricardo: trajetória política digital recente do agente ultracatólico do cristofascismo brasileiro
}

- Fábio Py

Doutor em Teologia pela Pontifícia Universidade Católica do Rio de Janeiro (PUC-Rio).

Professor na Universidade Estadual do Norte Fluminense Darcy Ribeiro (UENF).

Campos dos Goytacazes, RJ - BRASIL

lattes.cnpq.br/9482390225415714

pymurta@gmail.com

(D) orcid.org/0000-0002-7634-8615

Para citar este artigo:

PY, Fábio. Padre Paulo Ricardo: trajetória política digital recente do agente

ultracatólico do cristofascismo brasileiro. Tempo e Argumento, Florianópolis, v. 13,

n. 34, e0202, set./dez. 2021.

doi http://dx.doi.org/10.5965/2175180313342021e0202

Recebido: 17/05/2021

Aprovado: 22/10/2021 


\title{
Padre Paulo Ricardo: trajetória política digital recente do agente ultracatólico do cristofascismo brasileiro
}

\begin{abstract}
Resumo
A partir da História Política do Tempo Presente e da História Digital, o artigo destaca a atuação do Padre Paulo Ricardo, na construção de pautas político-religiosas que ajudaram na mobilização do projeto de extrema direita de Jair Bolsonaro até o poder. Ao considerar a noção de cristofascismo como uma "teologia do poder autoritário", o texto destaca os materiais utilizados pelo perfil de Bolsonaro nas redes sociais que foram replicados do perfil do padre; para isso, se vale da noção de "trajetória" de Giovanni Levi para traçar os últimos anos da atividade de Paulo Ricardo. Nesse sentido, a produção digital das redes sociais do padre alimenta o que se qualifica como cristofascismo de Bolsonaro, com temas da guerra dos deuses promovida pelo Estado cujos efeitos são o desprezo à ciência e contrariedade à pluralidade democrática.
\end{abstract}

Palavras-chave: Padre Paulo Ricardo; história política; história digital e cristofascismo.

\section{Father Paulo Ricardo: latest digital political trajectory of the ultra-Catholic liaison of Brazilian Christo-fascism}

\begin{abstract}
Based on the Political History of Present Time and Digital History, the article highlights the role of Father Paulo Ricardo in the construction of political-religious agendas thet helped to mobilize Jair Bolsonaro's extrme right-wing Project to power. When considering the notion of Christo-Fascism as a "theology of authoritarian power", the text accentuates the materials used by Bolsonaro's profile taken from the priest's profile, and borrowing the concept of Giovanni Levi's "trajectory" - a path, course taken - to draw the last years of activity of Paulo Ricardo. Hence, the digital production of the priest's social networks feeds what qualifies as Bolsonaro's Christo-fascism, with themes like the war of the gods promoted by the State whose consequences are the contempt for science and opposition to democratic plurality.
\end{abstract}

Keywords: Father Paulo Ricardo; political history; digital history and Christofascism. 
"Não é filme do Rambo, Brasil 'tá sangrando Essa brisa não bate, bala de veneno"

(Criolo)

\section{Introdução}

O governo de Jair Messias Bolsonaro, com início em 2019, se sustenta junto a um grupo denso de religiosos dos cristianismos hegemônicos, que asseguram o maquinário de sua gestão estatal. A historiografia do tempo presente (TEIXEIRA DA SILVA, 2020; TEIXEIRA DA SILVA, 2019; PY, 2020a) afirma que o Estado brasileiro se tornou um exemplo de "maquinário necropolítico" ao gerar "mortes dos indesejáveis" (MBEMBE, 2014) tendo o apoio do cristianismo ultraconservador negador da ciência e de ódio à pluralidade democrática.

Segundo Hobsbawn (2000), o cristianismo ultraconservador busca "reafirmar severamente as bases sociais desiguais do país, ligado a uma cultura autoritária" (HOBSBAWN, 2000, p. 65). No Brasil, existe uma variedade de cristianismos conservadores hegemônicos que se encontram à frente da reprodução social das religiões (PLEYERS, 2020); assim, considera-se pelo menos três diferentes formas que ajudaram na implementação do Estado de Bolsonaro: a primeira, os pentecostais ligados à teologia da prosperidade, que incham o discurso do governo de expressões diárias de fé como "bençãos" e "vitórias" (PY, 2020a; PY, 2020b); a segunda, os protestantes tradicionais (principalmente batistas e presbiterianos) que vernizam Bolsonaro com temas teológicos com enunciados que aludem o governante como aquele "eleito para governar a nação" (BOLSONARO, 2020b), e a terceira, a mais antiga, que se estruturou como central para o sistema político-religioso do país, o catolicismo conservador (BOLSONARO, 2020a; BOLSONARO, 2020b).

No artigo, destaca-se o ramo do catolicismo ultraconservador, no qual verifica-se pelo menos duas formas religiosas relacionadas ao bolsonarismo: os católicos tradicionais e o grupo da Renovação Carismática Católica. Para tratar sobre esse setor primordial da gestão Bolsonaro, foram selecionadas "cenas digitais" (NOIRET, 2015, p. 49) do padre Paulo Ricardo presentes nas suas redes sociais. Compreende-se como cenas digitas os "fragmentos digitais narrativos, 
ou descritivos, ou em vídeos, ou em imagens, ou mistos que direcionam uma mensagem complexa ou direta normalmente oriunda de uma rede social" (NOIRET, 2015, p. 114).

Dessa forma, reitera-se a relevância da análise das cenas digitais produzidas pelo padre Paulo Ricardo, por ser ele uma figura pública significativa do catolicismo atual, ao sintetizar referências do carismatismo e do ultraconservadorismo católico. Em consonância, argumenta-se que a partir das redes sociais, o padre atravessa os dois mundos católicos mediante a densa formação acadêmica, com passagens por instituições dos EUA e Itália, e por meio de sua prática pastoral inserida nas estruturas eclesiais do Mato Grosso.

Assim, o trabalho destaca a figura pública de Paulo Ricardo junto à política das elites do atual Estado pelas "continuidades que atravessam a ideologia dos governantes e o pensamento político” (RÉMOND, 1999, p. 54). Para isso, serão analisados materiais postados na forma de vídeos de curta duração e de fragmentos de textos (fontes mistas da web ${ }^{1}$ ) na rede social do padre (facebook), entre agosto de 2011 e 15 de julho de 2020, que repetidamente foram repostados por Bolsonaro no seu perfil do facebook, bem como os comentários do presidente sobre essas produções. Os vídeos foram transcritos e analisados com base numa pesquisa qualitativa e demonstraram a importância da produção do sacerdote para a construção da plataforma política do governo, tendo em vista que as redes sociais são lócus privilegiado da comunicação política bolsonarista (TEIXEIRA DA SILVA, 2020; TEIXEIRA DA SILVA, 2019; PY, 2020a; ALMEIDA, 2019).

Sobre isso, se observou que produções da rede social do padre Paulo Ricardo foram replicadas, ao todo, 17 vezes por Jair Bolsonaro (entre 2011 a 2020), o que possibilita traçar um fio de uma "história digital” de curta duração (SOSSAI \& MENDES, 2016; SEEGER, 2009; MANIVICH, 2005). Essa história é definida por Noiret (2015) "como todo o complexo universo de produções e intercâmbios sociais que têm como objeto o conhecimento histórico, transferido e/ou diretamente gerado [...] em ambientes digitais (pesquisa, organização, relatórios, difusão, uso público e privado, fontes, livros, métodos, performances, etc.)" (p.

\footnotetext{
'Fontes mistas de internet são formas que mesclam tipos diferentes de narrativas como textos, vídeos e imagens (SEEGER, 2009, p. 11).
} 
49). Portanto, o artigo apresentará uma trajetória digital do padre - trajeto esse marcado pela "descrição das atividades de personagens da internet como fontes historiográficas com características específicas, até, contando com amplo domínio de impacto desse material" (ROLLAND, 2004, p. 71). Considerando que uma "história digital tende a se relacionar mais com o serviço da web do que com outros serviços de Internet” (SOSSAI \& MENDES, 2016, p. 10).

Como se escreveu, o tratamento das fontes digitais, no fio de cenas digitais, que se irá desenvolver a trajetória do padre. A noção de trajetória aqui entoada é de Giovani Levi, que a caracteriza como um recorte, ou "uma parte das épocas da vida de sujeitos históricos (...) fragmentos de anos em uma biografia de vida” (LEVI, 2016, p. 76). A trajetória será formada por cenas digitais, e em cada uma delas, são tomadas primeiro como "ações políticas"2 (ROSANVALLON, 2015) digitais do padre, as quais foram repetidamente utilizadas como plataforma do presidente. A “ação política”, segundo Pierre Rosanvallon, tem uma conotação ampliada, abarcando, por exemplo, a "participação em greves ou manifestações, a assinatura de petições, a expressão de formas coletivas de solidariedade" (2015, p. 55). Logo, para o francês, na atualidade, não há um declínio da cidadania, mas uma ampliação dos repertórios: "existe uma nova configuração da ação política pela mudança (...) com a diversificação de seus repertórios e diversificação de alvos". Isso porque, diante da crise das "principais instituições de representação, organizações diversas se multiplicavam dando aos cidadãos outras formas de expressar suas queixas (...) apresentando novos locais para atividade do político" (ROSANVALLON, 2015, p. 57).

Metodologicamente, este texto assume que cada "cena digital" (NOIRET, 2015, p. 49) do padre se configura como uma ação política na web, ação essa que "aglutina diferentes vetores de pulverização no corpo social de afirmação e de distensão em relação ao status político" (ROSANVALLON, 2015, p. 61). Nesse sentido, a partir desse conjunto de conceitos da ciência histórica, compreende-

\footnotetext{
${ }^{2}$ A "ação política", para Pierre Rosanvallon, indica ser desde "participação em greves ou manifestações, a assinatura de petições, a expressão de formas coletivas de solidariedade" (ROSANVALLON, 2015, p. 55). Para ele, existe uma nova configuração da "ação política pela mudança, não um declínio da cidadania, com a diversificação de seus repertórios e diversificação de alvos”.
} 
se que o artigo atravessa tanto a história digital como também a história política do tempo presente. Tal linha é traçada porque "existem novas modalidades de experimento histórico sendo praticados no presente" (MANIVICH, 2005, p. 65). Portanto, é imprescindível a atualização do saber histórico, e nesse caso, apontase que além de cada cena digital ser uma ação política do padre, elas seriam também uma expressão da "guerra dos deuses" (mistura discursiva de religião e política nos estudos de religião de Michael Löwy [2000]) - fundamental para ascensão e a constituição do governo Bolsonaro.

Finalmente, assume-se neste trabalho que o padre é uma "persona midiática de impacto" (LEVÝ, 1999) antenada em múltiplas redes sociais e sites, agregando milhares de seguidores. Assim, para o desenvolvimento desse trabalho histórico, ele se dividirá em duas partes. Na primeira parte, a intenção é conceituar o cristofascismo, que marca a gestão de Bolsonaro. A segunda parte será dividida em dois pontos: o primeiro, uma pequena biografia do padre e a segunda, uma trajetória com a sequência de três cenas digitais da ascensão e das outras três cenas digitais com Bolsonaro no poder - todas retiradas do facebook do padre e replicadas pelo perfil de Bolsonaro. Logo, o intuito do artigo é mostrar como o religioso constrói um conjunto de ações político-religiosas que pavimentam a ascensão e hegemonia de Bolsonaro. Contudo, antes de descrever sua persona, iremos indicar o que se define como cristofascismo ou cristofascismo brasileiro.

\section{O cristofascismo brasileiro de Bolsonaro e seus intelectuais teológicos}

Para entender a "arquitetura política" (ROSANVALLON, 2015) formada pela cúpula governamental de Bolsonaro, observou-se a atuação de religiosos que assumem o lugar "intelectuais orgânicos” (GRAMSCI, 1982) digitais. Como intelectuais orgânicos digitais, pode-se citar o padre Paulo Ricardo e os pastores evangélicos, Silas Malafaia, Edir Macedo e Josué Valandro Junior.

Destaca-se que os mais importantes discursos de Bolsonaro feitos em rede nacional evocam o cristianismo, por exemplo, ao citar versículos bíblicos ou ao fazer uso de saudações cristãs (BOLSONARO, 2020a; BOLSONARO, 2020b). O 
cristianismo ultraconservador hegemônico defendido por essas lideranças religiosas promove uma "teologia política autoritária que escalona, molda o Estado" (SCHMITT, 1988, p. 21). Essa teologia política é pautada no cristianismo das Grandes Corporações Cristãs que solidificam uma política de "ódio à pluralidade democrática" (TEIXEIRA DA SILVA, 2020). É nesse sentido que buscase esclarecer nesta seção os elementos conceituais sobre o que vem sendo chamado de "cristofascismo brasileiro" (PY, 2020a).

O cristofascimo do governo Bolsonaro se refere à "política de ódio" (PY, 2020b), tonificado "pelas técnicas governamentais teológicas" (SCHMITT, 1988, p. 21) de promoção da discriminação ante os setores "heterodoxos" (BOLSONARO, 2020a; BOLSONARO, 2020b, PY, 2020a). Tais posturas puderam ser observadas em 2020, com a expansão da pandemia do corona vírus, no Brasil, quando foi amplificado o seu apelo antidemocrático de fôlego economicista contra a população mais pobre, os mais velhos e os portadores de doenças crônicas (BOLSONARO, 2020a; 2020b), o que justifica a "política da morte" (MBEMBE, 2014; BUTLER, 2020). O governo Bolsonaro e sua "teologia do poder estatal" (SCHMITT, 1988, p. 23) se projeta a partir do ultraconservadorismo cristão (ZEFERINO \& ANDRADE, 2020), pelo qual assume a "noção de família cristã brasileira a fim de promover a eliminação de seus adversários e dos indesejáveis” (PY, 2020b), neste caso, no contexto de Covid-19, os que não se adequam à faixa dos saudáveis.

O conceito de cristofascismo foi elaborado por Dorothee Sölle (1970), a partir da recordação sobre o nazismo alemão, especialmente em Auschwitz, no seu texto Beyond Mere Obedience: Reflections on a Christian Ethic for the Future (1970). O termo de Sölle se preocupa em apontar "as relações de integrantes do Nationalsozialistische Deutsche Arbeiterpartei (NSDAP - o partido nazi) com as igrejas cristãs no desenvolvimento do estado" (SÖLLE, 1970). A autora destaca que o governo nazista se utilizou das relações e terminologias cristãs para garantir a coesão social. Hitler utilizava jargões cristãos em seus discursos como o próprio "Conhecereis a verdade e a verdade vos libertará" (João 8,32) e "criou Deus, o homem à sua imagem; à imagem de Deus o criou; homem e mulher os criou" - a fim de defender a família tradicional cristã alemã (SÖLLE, 1970). O Führer participou de reuniões cristãs (luteranas, católicas e confessantes), 
relacionando-se com pastores e padres. Entre os luteranos, se destacaram os pastores Walter Hoff, Rudolf Kittel, Prospt Ernst Szymanowski, desenvolvedores do chamado "cristianismo positivo" (SÖLLE, 1970), religiosos tão importantes que cuidavam da produção teológica especializada.

A análise de Sölle (1970) não se restringe à Alemanha nazista. A teóloga amplia sua reflexão para extremistas brancos nos EUA, que teriam igual atitude de ódio, preconceito e racismo antes visto no regime imperial nazista. Ao descrever os grupos fundamentalistas nos solos americanos, a Sölle utiliza o termo "cristofascismo", como ação direta dos grupos supremacistas brancos nos EUA, não os relacionando com o Estado de forma tão direta. Assim, a autora não se preocupou com a conexão do cristofascismo como "uma teologia política autoritária que sustenta os estados, as governanças, as elites" (SCHMITT, 1988, p. 24). Aponta-o com o sentido teológico de uma "obediência cega", quando "nas relações com o divino de pessoas em regimes autoritários ou em grupos fundamentalistas" (SÖLLE, 1970, p. 65).

A autora pondera o "aprofundamento da compreensão unilateral do cristianismo (...) na Segunda Guerra Mundial e nos americanos no contexto das violências do extremismo dos fundamentalistas cristãos” (SÖLLE, 1970, p. 67). Assim, para ela, o cristofascismo é uma teologia característica da Igreja na Alemanha sob o nazismo, e ainda viva no final do século XX nos grupos extremistas brancos dos EUA. Com a expressão, defende que seja um "desvio do cristianismo fundamentalista a serviço do supremacismo branco e patriarcal, que se estende através da propagação do medo, dos socos, da misoginia e do racismo estrutural" (SÖLLE, 1970, p. 67).

Assim, pela força da narrativa de Sölle, argumenta-se no artigo que, no Sul global, desenvolveu-se outra modalidade de cristofascismo: "O brasileiro" (PY, 2020b); este seria uma conexão entre os grupos extremistas cristãos que, com “ações políticas" (ROSANVALLON, 2015), moldam as práticas de Bolsonaro. Nesse sentido, o cristofascismo brasileiro está preocupado com as vestimentas do que Carl Schmitt chama de "arquitetura do poder governamental" (SCHMITT, 1988), isto é, "nas modulações que os Estados se preocupam em significar o poder a partir dos grupos sociais e da autoridade do divino-governador, para o governo 
com imaginações teológicas autoritárias" (SCHMITT, 1988, p. 26). Dessa forma, a preocupação não é apenas com as descrições dos movimentos fundamentalistas como fizera Sölle.

Na "Teologia Política" (1922), Carl Schmitt compreende que "a arquitetura do poder autoritário" se inspira nas religiões monoteístas hegemônicas que, no caso brasileiro, seria o cristianismo. O governo de Bolsonaro é irrigado pelo fluxo teológico produzido por uma corrente de intelectuais acionados por sua gestão. Paulo Ricardo seria um desses intelectuais, que alimentam a atual gestão com prédicas, mensagens e imagens, ancorados numa teologia medieval do "CristoRei, também, do Deus-legislador como jurista humano - o soberano - da teoria do Estado" (SCHMITT, 1988, p. 27).

Também, não se pode deixar de reconhecer a fascinação autoritária (BENJAMIN, 2012) dessa acomodação brasileira, denominada aqui como cristofascismo, pois não representa um estágio de "regressão civilizacional", mas está contida nas próprias condições de reprodução da civilização liberalburguesa" (GAGNEBIN, 2014, p. 142). Neste sentido, para Benjamin (2012), o fascismo é um maquinário político de constituição do Estado de exceção, uma parte do rolo compressor, que migrou das técnicas governamentais que dominaram as colônias, aplicadas pela Europa e pelo Norte, e que hoje fundamenta o capitalismo global.

O fascismo também seria a "liberação das forças destrutivas produzidas por uma civilização burguesa em crise de forma a manter o processo de acumulação em funcionamento, o capitalismo" (BENJAMIN, 2012, p. 94). O filósofo entende que a fascinação imposta pelo governo autoritário se encaixa junto a concepções conservadoras da moral, da família e do progresso, para operar a transformação de todo nacional em um "Estado de exceção efetivo" (GAGNEBIN, 2014, p. 154). A gestão fascista ou neofascista, para Löwy (2020), condiciona um disciplinamento das massas proletarizadas para que não haja qualquer perturbação ao regime de propriedade posto. Trata-se de "permitir que tais massas se expressem enquanto massas, desde que a ordem posta não seja contestada e que quaisquer reivindicações que toquem na estrutura social sejam contidas" (BENJAMIN, 2012, p. 211). 
Por último, o cristofascismo opera politicamente uma guerra dos deuses, termo de Michael Löwy (2000) retirado da obra "Ciência como vocação", de Max Weber (1919). Com ele, Löwy (2000) aponta que os conflitos sobre "o politeísmo de valores e o conflito insolúvel das crenças básicas aos 'deuses' na sociedade moderna" (WEBER, 1998, p. 18), se reconhecem sobretudo nas diferentes disputas de narrativas religiosas que chegam às instâncias políticas do Estado. Assim, sinaliza que o termo:

se aplica ao conflito no campo religioso entre concepções de Deus radicalmente opostas: a dos cristãos progressistas e a dos cristãos conservadores (tanto católicos como protestantes) - uma 'coalisão de valores' (Wertkollision - outro termo weberiano) que, em situações extremas tais como a da América Latina na década de 80, pode até ser transfigurar em uma guerra civil. (LÖWY, 2000, p. 18)

O autor entende que nas sociedades latino-americanas ocorre a guerra de deuses, isto é, um embate entre "várias concepções de deuses como sintoma das lutas sociais tidas entre as sociedades civis e os estados" (LÖWY, 2000, p. 15). O bolsonarismo, apoiado nos seus intelectuais teológicos, opera uma sequência de ações políticas, pelas vias digitais, de lutas sociais como guerra dos deuses, ora simplificando, ora projetando uma fascinação da figura presidencial, associando-a ao caráter messiânico do cristianismo. Essa operação é tecida pelo corpo de intelectuais próximos ao governo que desenham a figura presidencial como um messias político, colocando-o como "salvador da pátria, firmado em Jesus" (PAULO RICARDO, 2018), ou ainda como "servo sofredor, ungido e eleito da nação no contexto da pandemia da Covid-19 no Brasil” (PY, 2020a).

O cristofascismo brasileiro vem influenciando politicamente os territórios do Sul como, por exemplo, mais recentemente pode ser observado nas novas modulações governamentais na Bolívia. Cita-se a coalizão cristã conservadora que tem a figura de Jeanine Añez, como presidente interina, a qual, diante de um golpe de estado, sinalizou que "A Bíblia voltou ao palácio" boliviano. Embora não seja intenção a análise do caso boliviano, destaca-se que existe o surgimento de outros governos autoritários no Sul, sustentados por discursos de intelectuais 
cristãos, para implementação de agendas ultraliberais ${ }^{3}$. Esse fenômeno se acopla numa modalidade de um "cristofascismo do Sul".

Após essas sinalizações, passamos a uma pequena biografia do padre Paulo Ricardo, e depois, a partir de sua produção intelectual (com seis postagens), indicaremos como vem sendo uma importante base político-religiosa da atual gestão presidencial.

\section{Quem é o Padre Paulo Ricardo?}

O Padre Paulo Ricardo de Azevedo Júnior é ligado à Arquidiocese de Cuiabá, Mato Grosso. Nascido em Recife (PE) no ano de 1967, em 1979 rumou com a família para a capital mato-grossense. Entre 1983 e 1984, fez intercâmbio e concluiu o Ensino Médio em Michigan, EUA, onde teve contato com os livros e as ambiências dos catolicismos conservadores norte-americanos (SILVEIRA, 2019). O contato ajudou na decisão de ingressar no Seminário em 1985, e em 1992, tornou-se sacerdote, com formação em filosofia e teologia. Defendeu o mestrado em Direito Canônico, pela Pontifícia Universidade Gregoriana, em Roma, no ano de 1993 (SILVEIRA, 2019).

Sua formação se deu entre os pontificados de João Paulo II e Bento XVI, extremamente conservadores na direção do diálogo da fé com o mundo contemporâneo. Atualmente, o padre exerce funções ligadas à pastoral e ensino em faculdades e paróquias: Vigário Paroquial em Cuiabá, Reitor do Seminário Cristo Rei, Secretário Geral do Sínodo Arquidiocesano de Cuiabá, Professor de Filosofia e Psicologia na Universidade Católica Dom Bosco, no Instituto Regional de Teologia e no Studium Eclesiástico Dom Aquino Corrêa - Campo Grande e Cuiabá (SILVEIRA, 2019).

Paulo Ricardo se conecta com o pensamento ultraconservador católico e tensiona com as demais tradições cristãs, principalmente as de matriz afrodiaspóricas. Dedica-se à escrita de livros e apresenta o programa semanal,

\footnotetext{
Quem assumiu um trabalho próximo a esse comparativo foi José Tamayo (2020), quando sustenta a noção de "cristoneofascismos", que se baseia numa expansão transnacional do ódio às pluralidades, comparando o crescimento das direitas nos últimos anos no mundo a partir de pautas ultraconservadoras cristãs.
} 
"Oitavo Dia", pela Rede Canção Nova de TV. Soma uma grande quantidade de serviços no seu site, cobrando por vídeos e aulas (SILVEIRA, 2019). Suas atividades são largamente difundidas, sendo o padre brasileiro com maior impacto na internet. A manutenção de seu instituto educacional em Cuiabá é financiada pelos cursos que ministra na internet. Todo serviço nos sites é feito por uma equipe intitulada Christo Nihil Praeponere, o que significa em latim: "A nada dar mais valor do que a Cristo" - sua “identidade visual” (SILVEIRA, 2019, p. 289-309).

Cada vídeo postado no Youtube pelo padre tem um breve comentário explicativo resumindo a ideia central da fala ou da conferência. Em muitos deles, é vetada a inserção de comentários, o que dificulta a propagação de polêmicas e de críticas negativas. A maioria das postagens do padre são autorreferentes. A imensa atividade do padre como professor e palestrante está contida nas redes sociais eletrônicas, o que amplifica suas oportunidades de participar de eventos de massa e apresentar um programa de TV na Comunidade Canção Nova (SILVEIRA, 2019).

Essa atividade ganhou tamanha proporção que, por exemplo, o noticiário “Diário de Cuiabá" publicou uma reportagem intitulada "Padres pedem a bispo que Padre Paulo se cale. Em carta endereçada a arcebispo, 27 padres pedem que padre seja proibido de pregar" (SILVEIRA, 2019, p. 300). Contudo, o texto sinaliza que ocorreu um apoio radical dos fiéis católicos ao padre. Por outro lado, podese destacar sua constante atuação no Congresso junto a políticos confessadamente católicos e evangélicos. No fim, a soma de controvérsias ajuda na mobilização, até porque elas são divulgadas pela mídia religiosa que dá ao padre mais exposição e propaganda; tudo com anuência do bispo diocesano, Dom Milton Santos (SILVEIRA, 2019).

Emerson Silveira (2019, p. 301) indica que os "apoios recebidos de milhares de fiéis vêm também por sua desenvoltura discursiva que retroalimenta seus perfis e páginas eletrônicas, em um movimento contínuo". Esse circuito beneficia a construção de uma intensa guerra dos deuses (LÖWY, 2000) trilhada na leitura restritiva da tradição católica contra quem ameaça a "família tradicional cristã brasileira”, tal como defende a Frente Parlamentar Evangélica (PY, 2020b) tentáculo ultraconservador que frequentemente convoca-o para palestras. 
Introduzida essa persona emblemática do ultraconservadorismo brasileiro, apresenta-se uma "sequência digital" (NOIRET, 2015, p. 53), fruto do “mapeamento de suas produções emblemáticas das redes sociais" (ROLLAND, 2004, p. 75-79) selecionadas pela sequência de replicações do facebook de Bolsonaro. Nesse caso, destacam-se, abaixo, seis ações políticas (três de ascensão e três de manutenção de Bolsonaro) do padre que são utilizadas como plataforma digital para o governo.

\subsection{Ações web-políticas de Paulo Ricardo para ascensão de Bolsonaro}

Nesse item, a intenção é descrever as primeiras três ações políticas construídas pelo Padre Paulo Ricardo pela via digital (NOIRET, 2015), na forma de cenas da web como "partes essenciais para compreender as mensagens e os objetivos sociais" (LEVÝ, 1999, p .76), enquanto articulador político-religioso da ascensão de Bolsonaro.

A primeira ação política do padre pela via digital selecionada é sobre a questão da liberalização das armas de fogo no país, uma pauta central de Bolsonaro, desde os primeiros momentos de sua atividade política. No vídeo "A igreja e o desarmamento"4, ainda de 2011, afirma que "o plebiscito era para tirar armas legais, da mão dos brasileiros (...) numa abordagem superficial, você pode pegar o catecismo a respeito da guerra, e você irá encontrar ali uns parágrafos bem suculentos na mão, aqueles que são a favor do desarmamento (...) A igreja é a favor do desarmamento. Errado, luz vermelha para você" (PAULO RICARDO, 2011). No ano de 2011, Bolsonaro era deputado federal pelo Partido Progressistas, e começava a construir argumentos pela ampliação da liberação do porte de armas (TEIXEIRA DA SILVA, 2020; ALMEIDA, 2019).

Após os primeiros contatos de Paulo Ricardo com a família de Bolsonaro, que ocorreram em Araraquara em 2011 (ALMEIDA, 2019), o padre produziu o vídeo em consonância com as pautas do parlamentar. Nessa produção digital ele indica

\footnotetext{
O vídeo foi postado no facebook de Bolsonaro (2020a; 2020b), em cinco momentos, seja editado em partes, seja por completo. Nas seguintes datas: 14/02/2012; 02/02/2013; 21/10/2013; 14/07/2018; 02/10/2019. Na última postagem, o perfil de Bolsonaro escreveu "As armas garantem nossa liberdade, o cristianismo nos indica isso".
} 
que a Igreja não é contra o armamento da população, e que as armas seriam necessárias em casos de ameaça. No vídeo indica: "no contexto bem específico de corrida armamentista (...) é a favor de diminuir essas armas tão letais, de armas de destruição em massa (...) Entendamos meu irmão: o cristão é pacífico, não pacifista" (PAULO RICARDO, 2011). Entretanto, o padre argumenta ser necessário armar a população no caso de invasão de propriedades: "é um dever, um assaltante que entra na sua casa, violenta sua filha, violenta sua esposa, dilapida seus bens, o que você fará? Você dirá que é a favor da paz? Você terá coragem de olhar para sua filha, sua esposa e olha eu não fiz nada, não porque sou um covarde, mas porque sou pacifista” (PAULO RICARDO, 2011).

Nesse material, o padre fundamenta o direito da população a ter acesso às armas. Segue o mesmo tom do discurso de Bolsonaro de janeiro de 2011, na Associação Hebraica do Rio de Janeiro (ALMEIDA, 2019), quando desenvolve o seu raciocínio, traçando uma relação entre armas de fogo, segurança da classe média, propriedade privada, e a defesa da família e da Igreja. Na cena digital, o padre indica que a Igreja Católica é contra as armas de extermínio em massa, mas não contra as armas de fogo, individuais (PAULO RICARDO, 2011). Ele indica que o uso da violência é permitido em caso de defesa da propriedade e da família, com vocabulário cristão e sob as bênçãos da cúria.

O vídeo teve impacto nas mídias digitais, e Bolsonaro o repostou cinco vezes nas suas redes sociais. Na quarta vez que divulgou o vídeo, escreveu: “armar a população (...) para que sejamos livres de verdade" (BOLSONARO, 2020a). Portanto, o posicionamento político do padre serve de base para a guerra dos deuses (LÖWY, 2000) da política armamentícia de Bolsonaro, ajudando-o no argumento de armar a população em nome do divino, como escreveu na sequência da postagem "armar a população é um sinal de liberdade para a defesa pessoal de cada indivíduo" (BOLSONARO, 2020a).

A segunda cena digital de Paulo Ricardo foi mais recente, em 2017, na forma de vídeo intitulado "A imbecialização do país" (PAULO RICARDO, 2017). O vídeo foi postado nas redes sociais de Bolsonaro (2020a; 2020b), em três momentos. No dia 14/12/2014, ele foi postado em partes, e nos dias 03/05/2016 e 12/04/2020, foi postado de forma completa. O perfil de Bolsonaro escreveu 
"Defendemos nossas criancinhas do gramcismo". O material trata da questão do gramscismo (RICUPERO, 2010, p. 76-94), o qual, para o setor ultraconservador brasileiro, seria a "reunião de um pensamento que articula os processos revolucionários de tomada de pensamento liberal nos usos e costumes, comunista, popular". Um antagonista que se moveu "contra o pensamento conservador, contra a direita e a fiel família cristã. É contra eles que uma elite mundial pervertida luta diariamente para tomar os espaços conservadores" (RICUPERO, 2010, p. 90).

A cena digital, na forma de vídeo, foi gravada em uma palestra do padre quando, novamente, utiliza o raciocínio persecutório ironizando as tendências de norma "culta" e a "linguagem popular" como sendo uma raiz dos problemas sociais que se vive no Brasil e no mundo (PAULO RICARDO, 2017). Faz isso assumindo uma acusação genérica, culpando os professores por passarem para os alunos "um texto social, com a pretensão de fazer política, quando se paga para ensinar português" (PAULO RICARDO, 2017).

No vídeo-web postado na rede social facebook, sem dados ou fontes, o padre vestido de trajes religiosos, logo munido do simbólico sacerdotal, acusa os professores de séries iniciais de tentarem traçar um processo silencioso no ambiente de sala de aula para incutir uma politização das crianças e adolescentes. Com ele, culpa a classe professoral por ocasionar uma "lenta e gradual imbecialização de uma nação" (PAULO RICARDO, 2017). De acordo com o padre, os professores fazem isso para causar uma baixa reflexão, e facilitar o domínio "esquerdista" do país. Além disso, ele aciona uma "teoria da conspiração" (TEIXEIRA DA SILVA, 2020) de que os professores constroem um conluio comunista quando distinguem norma "culta" e a "linguagem popular" (RICUPERO, 2010, p. 90). Nessa ação política acusatória, indica que "ao invés de ensinarem o português, estão aprendendo cartilha marxista”. Pois, segundo ele, "afinal de contas se eu quero implantar o socialismo (...) se eu quero dominar uma sociedade nada melhor que dominar uma classe de idiomas" (PAULO RICARDO, 2017). Ao fazer isso, o padre constrói uma acusação "típica das elites brasileiras que preferem acusar o setor professoral de conluios para não reconhecer a importância do setor para a construção do país" (MASSENBERG, 
2007, p. 91) e atua na construção das guerras dos deuses ante ao estado plurirreligioso.

Em seu discurso, o padre se conecta com as teorias da conspiração propostas pelo intelectual da ultradireita Olavo de Carvalho, que trata do "foro de São Paulo, de uma organização criada por Lula e Fidel Castro, baseada nos marxismos e no liberalismo dos costumes, que usa Gramsci como método de tomar mentalidades" (MASSENBERG, 2007, p. 72). O padre segue o script olavista, ao indicar que os professores "não querem que você aprenda nada, que você estude nada, para estudar, do jeito que eles querem, isso é o gramscismo na prática" (PAULO RICARDO, 2017). Afirma ainda que "mesmo que você não tenha ouvido falar de Antônio Gramsci você é um profundo conhecedor de Gramsci (...) um conhecedor prático, porque foi vítima dele” (PAULO RICARDO, 2017). Essa cena da web, envolvida em tom persecutório, é repleta de um "caminho de desinformação", tal como Francisco Teixeira da Silva (2020) escreve.

Assim, o padre aciona uma linha de raciocínio comum do conservadorismo brasileiro atual, o qual despreza a docência e se notabiliza com o discurso de uma "guerra cultural", uma vez que existe um complô mundial contra "a verdade da família cristã” (PAULO RICARDO, 2017). Esse argumento faz parte da construção do cristofascismo contra aqueles que pertencem ao "esquerdismo cultural” (PAULO RICARDO, 2017). O padre verbaliza a distinção de modo culto e coloquial como parte de "extrema guerra cultural, no qual, para ele, é um sinal do ateísmo, do comunismo mundial que tomou conta do Brasil" (MASSEMBERG, 2007), transformando em parte da guerra dos deuses, sendo evocado em nome de Deus - na sua defesa por Bolsonaro.

A terceira ação política de apoio à ascensão de Bolsonaro, na forma de cena digital, ocorreu no contexto das eleições presidenciais de 2018. Quando o padre ministrou um curso em uma paróquia (SILVEIRA, 2019). Nele, o padre indica sua vinculação com o projeto de Bolsonaro, quando citou diretamente a facada que o então candidato sofreu durante as eleições. O material foi gravado na forma do vídeo, intitulado: "padre Paulo Ricardo se pronuncia sobre o atentado contra Bolsonaro e o vídeo viraliza na web" (PAULO RICARDO, 2018), do dia 11 de setembro de 2018. Esse vídeo foi postado nas redes sociais de Bolsonaro (2020a; 
2020b), uma vez no dia 02/04/2019, em que Bolsonaro escreve: "Apoio do padre Paulo Ricardo", e no dia 11/10/2020, escreveu "Para aqueles que riram de nosso governo”. O vídeo é uma cena digital curta, porém elucidativa na vinculação do padre com a figura de Bolsonaro. Em poucas palavras o padre diz durante uma apresentação: "Como você cala a boca das pessoas? Ou você dá uma facada.... (a plateia diz: mito! Mito! Mito!)”.

No material, se percebe o apoio da plateia e do padre a Bolsonaro, quando no discurso não pede para as pessoas se acalmarem diante da citação ao candidato (PAULO RICARDO, 2018; PY, 2020a). Na afirmação, indica que a facada sofrida, no âmbito das eleições de 2018, “foi uma tentativa de calar o candidato", e enfatiza que há uma "guerra contra o candidato à presidência" (PAULO RICARDO, 2018). O padre desenha Bolsonaro como mártir - um elemento típico do "cristianismo do poder" (SCHMITT, 1988; PY, 2020a) -, a evocação das "perseguições sofridas pelos cristãos desde o surgimento do cristianismo no contexto da Roma Antiga" (BOFF, 1974). Ao mesmo tempo, a figura de mártir alimenta a trama da perseguição fundamental para o desenvolvimento do cristofascismo.

Na sequência da produção digital (NOIRET, 2015), o padre lembra de um papa representativo do catolicismo conservador, Bento XVI. Ele diz "ou você realiza aquilo que Bento XVI chama de 'martírio dos tempos modernos', que é caluniar, desacreditar, inventar mentiras sobre essas pessoas" (PAULO RICARDO, 2018). Portanto, o tom de adesão a Bolsonaro, com vocabulário ultracatólico, indica que tentam produzir mentiras que visam desacreditá-lo, construindo sobre o candidato um "martírio dos tempos modernos" (PAULO RICARDO, 2018). Logo, assume Bolsonaro como "um cristão verdadeiro" (PAULO RICARDO, 2017) que passa por perseguição política como candidato do cristianismo, logo "contra o esquerdismo" (PAULO RICARDO, 2017).

Nesse material político da web, o padre incentiva a construção da mentalidade persecutória cadente na política de Bolsonaro - o que se aprofundou na gestão presidencial (TEIXEIRA DA SILVA, 2020) ao utilizar o material por duas vezes no facebook presidencial, escrevendo: "Deus me deu uma missão de levar a nação" (BOLSONARO, 2020a). Dessa forma, o vídeo 
desenvolve sobre a lógica comum no ramo mais conservador do cristianismo que evoca a centralidade da "via crucis como caminho paradigmático dos verdadeiros cristãos" (BOFF, 1974, p. 63).

Portanto, o religioso sinaliza que existe uma operação de transformação da figura de Bolsonaro em um mártir cristão, justamente nas eleições, e alimenta o ritmo do raciocínio de perseguição, por meio da linguagem teológica. Reforça, assim, o que Bolsonaro escreveu no facebook: "ser como Cristo, que sofreu ataques de todos os lados, mas mesmo assim venceu" (BOLSONARO, 2020a). Com a cena, promove a guerra dos deuses, com categorias teológicas, contra os demais setores sociais, alimentando a política posterior da gestão de Bolsonaro. Tanto que o presidente repetidamente argumentou na rede social, na época da Páscoa de 2020: "todos se levantam para calar, todos querem me silenciar, mas não irão (...) eu sou como cristo, perseguido” (BOLSONARO, 2020a).

\subsection{Ações web-políticas de Paulo Ricardo no governo Bolsonaro}

Nesse item será analisada a sequência de ações políticas digitais do padre feitas durante a pandemia de Covid-19 e sua adesão aos caminhos do governo Bolsonaro. O vídeo escolhido foi postado no dia 22 de março de 2020, durante o segundo ano do mandato do presidente, chamado de "A igreja prostrada diante de um vírus" (PAULO RICARDO, 2020a). Nele, o padre passa a comentar teologicamente o acontecimento mundial da pandemia (CASTRO, 2021). O vídeo foi repostado nas redes sociais de Bolsonaro (2020a; 2020b) três vezes. Nos dias 10/02/2020, 19/05/2020 e 21/04/2021 - quando foi divulgado de forma completa. Naquele dia, o perfil de Bolsonaro escreveu "Obrigado Nossa Senhora por essa palavra".

Esse material foi a primeira produção político-teológica de Paulo Ricardo sobre o impacto da Covid-19, diante dos primeiros casos do vírus em Mato Grosso. O motivo de sua criação foi a notícia de que o vaticano iria fechar as paróquias diante da catástrofe da pandemia. Ele abre o vídeo questionando: "terá a Igreja perdido a fé? (...) os nossos bispos sendo covardes, ao cancelarem e privarem as almas do conforto dos sacramentos?” (PAULO RICARDO, 2020a). 
Essa cena digital espalha uma série de questionamentos sobre a doença e se baseia nas discussões do Concílio Vaticano I, que moldaram o concílio e tratam do "fideísmo". O fideísmo é uma doutrina na qual "as verdades metafísicas e morais, como existência do divino, são inalcançáveis à razão humana, só sendo compreendidas por meio da fé” (AZEVEDO, 2003, p. 19). Os fideístas não se preocupam com as argumentações que visam apoiar sua a fé no divino, sem racionalização, ao mesmo tempo, se contradiz ao buscar a razão para expor seu pensamento. Nesse sentido, Demi Azevedo indica que o fideísmo "teme a razão: se faz como um tipo de fé cega" (AZEVEDO, 2003, p. 90).

Os debates levados pelo Papa Pio IX indicam o fideísmo como vertente que entende que "as questões religiosas não podem ser justificadas por meio de argumentos ou provas, mas pela fé" (AZEVEDO, 2003, p. 90). Assim, o padre retoma esse raciocínio importante para o setor ultracatólico brasileiro. Nessa operação teológica, deixa de lado a renovação da teologia católica que ocorreu com o Concílio Vaticano II. Ao voltar o argumento a Pio IX, o padre diz que o problema não é apenas com a afirmação fideísta (que é "só a fé") ou do “racionalismo (...) só a razão" no contexto da pandemia. Para ele, a questão é diante da peste, por meio da fé, com rezas e súplicas pode-se "obrigar a Deus a interferir na história humana com a abertura das paróquias" (PAULO RICARDO, 2020a).

Na cena digital, afirma que a questão da construção de uma série de ações de devoção pode "obrigar a Deus a fazer um milagre" (PAULO RICARDO, 2020a). Assim, utiliza do texto do Novo Testamento, a narrativa de que o diabo fez com Jesus no fragmento dos Evangelhos. Indica: "abrir as portas das paróquias (...) é tentar a Deus. Porque está obrigando ao Deus a fazer o milagre!” (PAULO RICARDO, 2020a). No raciocínio afirma que ser católico "e fideísta? (...) Isso é loucura!”. Nesse sentido, em termos da história da teologia cristã, o padre se preocupa em fechar as paróquias "para não obrigar a Deus a fazer milagres" (PAULO RICARDO, 2020a). Afirma que não irá abrir a igreja: para "não tentar a Deus - como o diabo fez segundo a narrativa dos evangelhos" (PAULO RICARDO, 2020). 
Portanto, no meio dos embates político-sociais causados pela pandemia do Covid-19, o padre se desvincula das discussões da ciência pelo isolamento social para evitar aglomerações para diminuir o contágio. Nessa linha discursiva assume a posição de Bolsonaro da época, quando deviam-se impedir "as celebrações para não se obrigar ao divino a realizar milagres" (BOLSONARO, 2020a), como o presidente escreveu à época sem argumentar sobre a ciência.

Outra ação política da web destacada, ocorreu no dia primeiro de abril de 2020, próximo à Páscoa, quando lançou mais um vídeo da série sobre o Covid19. No material se propõe a responder à pergunta: "O Covid-19, e outras pestes, são castigos de Deus"5 (PAULO RICARDO, 2020b). Nessa, volta a seguir a linha argumentativa do governo Bolsonaro de forma explícita indicando que devia-se pensar na economia e não se fazer no âmbito da sociedade um isolamento social total (PY, 2020a). Assim, faz algumas indagações teológicas em termos de história da Igreja: "se ele (Deus) é um pai bondoso e compassivo, como permitiria tamanhos males sobre os inocentes?" (PAULO RICARDO, 2020b).

Abre sua argumentação da web com a tese ultracatólica: "o problema da humanidade é o pecado” (PAULO RICARDO, 2020b), tal como Bolsonaro já tinha argumentado no facebook "o Covid-19 é um sinal que a humanidade não está bem com Deus" (BOLSONARO, 2020b). Assim, o padre postula que o problema dos milhares de mortos "no mundo é o pecado". Ele trata toda realidade sóciohistórica segundo uma máxima transcendental, algo comum no trajeto ultraconservador cristão. Com o argumento, salienta que é o "pecado que está matando as pessoas" (PAULO RICARDO, 2020b). Portanto, a partir do vídeo tece o apoio à guerra dos deuses importante para o governo Bolsonaro, expondo uma compreensão teológica comum, ou melhor, um juízo teológico como argumento sobre o político.

Na sequência da cena digital evoca: "Nosso Senhor Jesus Cristo sofreu na Cruz, não por causa dos seus pecados, mas pelos nossos. (...) O sofrimento é

\footnotetext{
O vídeo foi postado nas redes sociais de Bolsonaro (2020a; 2020b), duas vezes. No dia 15/06/2020 e no dia 20/12/2020. Em ambas as postagens, Bolsonaro escreveu "Atentos aos juízos de Deus".
} 
sinal dos nossos pecados, do pecado original, do pecado que fazemos" (PAULO RICARDO, 2020b). Na afirmação, radicaliza a história da dogmática cristã colocando que o "sofrimento e a morte são sinais do pecado original da humanidade" (PAULO RICARDO, 2020b). Utiliza um truque típico do universo cristão conservador (WEBER, 2000), ao indicar que "não qualquer pecado, mas sim, o pecado original que manchou toda humanidade" (PAULO RICARDO, 2020b).

A produção da ação política digital na forma de vídeo ocorreu com o aumento exponencial de mortes pela Covid-19, em 2020. Logo, nesse contexto, o padre, uma base da guerra dos deuses de Bolsonaro, evoca a ideia do pecado original, para "justificar parte do ódio à diversidade de experiências sócioreligiosas" (PY, 2020a, p. 54). Para isso, na sequência, segue o raciocínio comparando o sofrimento atual ao martírio de Jesus: "O que estou sofrendo não é nada, diante do que sofreu por mim na cruz" (PAULO RICARDO, 2020b). Coloca "todo sofrimento sobre o plano do sofrimento que Jesus teria sido exposto na crucificação" (BOFF, 1974, p. 113), tal como salienta Leonardo Boff, seria uma postura típica do cristianismo ultraconservador.

No fim dessa ação política digital, volta ao tom do vocabulário de Bolsonaro, ao chamar a pandemia de "histeria coletiva" (PAULO RICARDO, 2020b). Tanto que o presidente postou nas suas redes o vídeo, colocando sobre o divino tal efeito, com a frase: "atentos ao juízo de Deus ao Brasil". O padre e a cúpula de Bolsonaro, mesmo com milhares de mortos no Brasil, compreendem a pandemia do Covid-19 como parte da "histeria coletiva" e que serviria para a “pedagogia divina” (PAULO RICARDO, 2020b). Nessa linha de raciocínio, o que se está passando com a pandemia são pequenos ensaios do "sofrimento que virá para a Igreja no futuro" (PAULO RICARDO, 2020b). Portanto, nessa ação política, o padre expõe seu conservadorismo cristão, a partir da linguagem teológica, ao indicar que a pandemia é apenas um "treino do que passaremos no futuro e que apenas alguns irão sobreviver" (PAULO RICARDO, 2020b). Bolsonaro se apropria dessa tese teológica e aprofunda sua guerra dos deuses ao salientar que a parcela dos sobreviventes são "homens e mulheres eleitos por Deus e pela santa Igreja Católica Romana que farão a nação brasileira melhor" (BOLSONARO, 2020b) - sintoma de seu cristofascismo brasileiro. 
Na última produção, aqui selecionada da web, do padre Paulo Ricardo, de 2013 até 2020, ele estabelece uma outra teologização das questões imanentes. É o único material que não se encontra na forma de vídeo, mas sim na forma de artigo intitulado "Pandemia e os quatro cavaleiros do apocalipse" (PAULO RICARDO, 2020c), publicado no dia 15 de julho de 2020, em seu site pessoal. O artigo foi repostado nas redes sociais de Bolsonaro (2020a; 2020b) duas vezes, nos dias 20/11/2020, 03/02/2021. Nas duas oportunidades, o perfil de Bolsonaro escreveu "Palavras de Deus para nós, para o Brasil". No texto, o padre trata da questão das doenças, pragas, ciclones, terremotos, guerras políticas e sociais que se vive desde o início de 2020. Ele desenvolve sobre o signo do Evangelho de Mateus 24,8, que diz: "de fato, há de levantar nação contra nação e reino contra reino. Haverá fome e terremotos em vários lugares. Tudo isso é o começo das dores".

Ou seja, ele acena teologicamente no artigo, ao utilizar o Evangelho de Mateus, para indicar que o "Covid-19 seria apenas o início dos problemas da humanidade" (PAULO RICARDO, 2020c). Com isso, tira o foco da gestão Bolsonaro, e, ao mesmo tempo, trata das "pragas que são o início do fim do mundo que está por vir, que ele é na verdade, um treino para um futuro próximo" (PAULO RICARDO, 2020c). Na produção da web, o padre evoca a ideia do início da história da Igreja da "Grande Tribulação" (PAULO RICARDO, 2020c) para alimentar o raciocínio do setor do cristianismo ultraconservador do qual faz parte.

Rubem Alves sintetiza esse argumento ao escrever sobre algumas interpretações do Apocalipse, "que apenas algumas pessoas serão salvas, eleitas que desfrutam da face do divino, que é um Deus do alto, despótico que penaliza o resto de toda humanidade" (ALVES, 1975, p. 41). Na ação política digital, ele liga no mesmo raciocínio, o Evangelho de Mateus, a peste e a purificação. Assim, resume o argumento central teológico de seu artigo, assim: "A 'peste', a 'fome' e a 'guerra' estão biblicamente ligadas à purificação pela qual os homens precisam passar" (PAULO RICARDO, 2020c).

Nessa tese ultraconservadora, há "um cristianismo exclusivista, uma política eugênica sócio biológica” (PY, 2020b, p. 17). Novamente, o padre 
fundamenta teologicamente o governo diante da pandemia evocando o ideal cristão de reafirmar o triunfo de alguns "separados por Deus" (ALVES, 1975, p.61), esses que serão os "puros" (PAULO RICARDO, 2020c) mediante o castigo da peste Covid-19.

Nessa linha, o padre auxilia na tessitura da "teologia do poder autoritário" (SCHMITT, 1988) de Bolsonaro quando pouco depois do discurso da postagem do padre, o próprio presidente afirmou que aprendeu no cristianismo (católico) que "a pandemia também vai nos tornar melhores, no fim Deus vai triunfar" (BOLSONARO, 2020b). Sobre esse material, Bolsonaro escreve na rede "Palavras de Deus para nós, para o Brasil”, confirmando e dando status de divina a mensagem do padre, além de evocar a ideia da nação.

Assim, pelo conjunto de referências e de replicações nas redes sociais de Bolsonaro, afirma-se que a política do presidente está conectada às ações de Paulo Ricardo, que formula subsídios para a construção dessa modulação governamental do cristofascismo brasileiro. No caso, a teologia ultraconservadora do padre apoia com ações políticas a guerra dos deuses, centrais para o governo, na qual indica a importância social das mortes em meio à pandemia.

Na produção histórica digital, o padre admite que os cataclismas que ocorrem na humanidade servem para a "purificação" - pensamento ligado a base do cristofascismo de Bolsonaro eugênico - que entregou a população às consequências da peste do Covid (PY, 2020b). O padre Paulo Ricardo sustenta o argumento apelando às sociedades bíblicas, de que as pessoas que sobrevivem aos grandes desastres são aquelas que não são expostas às doenças, não passam fome ou não vão para guerra. Logo, sua sentença teológico-política, é de desprezo às questões sociais, de não reconhecimento da importância do contexto social para evocação teológica.

Como já se indicou, algo comum nos setores ultraconservadores que enfatizam os sistemas teológicos em detrimento dos demais aspectos da vida social. Portanto, nessa pequena trajetória histórica digital da persona digital do padre reconheceu-se uma diversidade de temas caros ao bolsonarismo como: o apelo às armas para defesa de parte da população; os dizeres da guerra dos 
deuses, de um deus verdadeiro contra os demais; da eleição divina de Bolsonaro; o presidente como servo sofredor, como cristo e etc. Todos esses elementos somados dão força ao que Butler (2004) afirma sobre as modulações eugenistas intrínsecas às sociedades cristãs e suas formações de Estados.

\section{3. Últimas indicações}

O artigo buscou traçar uma linha complexa entre história política do tempo presente e a história digital, utilizando o conceitual de cena digital. Traçou-se um fio de cenas digitais indicadas como uma trajetória histórica digital da figura importante do catolicismo ultraconservador, o padre Paulo Ricardo, a partir de suas publicações de vídeos e de um artigo no meio midiático de 2011 a 2020, que foram 17 vezes utilizados nas redes sociais de Bolsonaro e também comentadas nas suas postagens. Logo, serviu de apoio político direto para o atual governo, parte de sua "teologia do poder autoritário".

As cenas digitais funcionaram como um conjunto de ações políticas (ROSANVALLON, 2015) do padre que demonstram "uma ampliação não só eleitoral das intervenções políticas" (ROSANVALLON, 2015, p. 65), mas principalmente da organização do pensamento político da extrema-direita bolsonarista. Nesse caso, a partir da conexão da nova história política e da história digital, se buscou traçar a figura do padre e como ele vem alimentando com tons cristãos a construção política da figura de Bolsonaro, importante para seu cristofascismo brasileiro (PY, 2020a), repleta de signos de um deus do alto, despótico, servo sofredor, martirizado, o qual seleciona algumas pessoas em detrimento da sociedade.

O artigo sinalizou Paulo Ricardo como um articulador da ascensão de Bolsonaro ao poder e de apoio a sua gestão, ajudando a mobilizar uma série de temáticas importantes para a guerra dos deuses, tais como: a teoria da conspiração que coloca os professores como ponta do gramscianismo no Brasil; acusa as esquerdas de tentarem calar Bolsonaro; defende o armamento da população brasileira; afirma que a pandemia é apenas um detalhe, e que ocorre uma "histeria coletiva com essa gripezinha" (BOLSONARO, 2020b). Contudo, sua "produção política” (ROSANVALLON, 2015) mais densa relaciona a teologia 
conservadora católica à pandemia. O padre como mobilizador ultracatólico, escreve a fórmula complexa de que o "divino com a pandemia não visa apenas ensinar, mas, sobretudo, purificar a nação brasileira” (PAULO RICARDO, 2020c).

Nesse sentido, destacou-se que o canal de conexão do padre com a cúpula bolsonarista foi denso, de tal forma que as suas produções da web foram repetidamente postadas nas redes sociais oficiais do presidente Bolsonaro, auxiliando a construção digital do cristofascismo brasileiro. Assim, a trajetória histórica mais recente do padre é peça-chave da política de Bolsonaro, operando de forma distinta de Silas Malafaia, estrondoso evangelista. Paulo Ricardo tampouco age de forma tão tecnológica como o pastor batista Valandro Junior, mas sim, trata dos temas caros a Bolsonaro, seguindo o script da formação católica, isto é, com poucos gestos e a mansidão na fala. O padre se faz como uma base para a construção do governo Bolsonaro que, politicamente, prefere desacreditar a ciência em prol de uma teologia ultraconservadora.

\section{Referências}

ALMEIDA, R. Bolsonaro presidente: conservadorismo, evangelismo e a crise brasileira. Novos Estudos Cebrap, p.185-215, 2019.

ALVES, R. O enigma da religião. Petrópolis: Vozes, 1975.

AZEVEDO, D. Desafios estratégicos da Igreja Católica. Lua Nova, n.60, 2003.

BUTLER, J. Undoing gender. Nova York: Routledge, 2004.

BOFF, L. Jesus Cristo libertador. Petrópolis: Vozes, 1974.

BOLSONARO, J. M. Instagram, 2020. Disponível em:

https://instagram.com/jairmessiasbolsonaro. Acesso em 03 junho de 2020 a.

BOLSONARO, J. M. Pronunciamento do presidente da República. Jair Bolsonaro (08/04/2020). Youtube, 8 de abril de 2020. Disponível em:

https://www.youtube.com/watch?v=x040KkxT2Tc. Acesso em 03 de junho de 2020b.

GAGNEBIN, J. M. Limiar, Aura e Rememoração. São Paulo: Editora 34, 2014. 
Padre Paulo Ricardo: trajetória política digital recente do agente ultracatólico do cristofascismo brasileiro

Fábio Py

HOBSBAWN, E. O novo século. São Paulo: Companhia das Letras, 2000.

IGREJA BATISTA GETSÊMANI. Clamor e jejum pelo Brasil - 05 ABRIL -

Convocação do presidente Jair Messias Bolsonaro. Youtube, 4 abr. 2020.

Disponivel em: https://www.youtube.com/watch?V=MV7VR1ZX19Q. Acesso em:

06 maio 2020.

LÉVY, P. Cibercultura. São Paulo: Editora 34, 1999.

LOWY, M. A guerra dos deuses. Petrópolis: Vozes 2000.

MBEMBE, A. Crítica da razão negra. São Paulo: Antigona, 2014.

MANOVICH, Lev. Novas mídias como tecnologia e ideia: dez definições. In: LEÃO, Lu-cia (Org.). O chip e o caleidoscópio: reflexões sobre as novas mídias. São Paulo: Senac, 2005

MASSENBERG, D. A direita saiu do armário: a cosmovisão dos formadores de opinião dos manifestantes brasileiros. Sociedade e Estado, v.32, n.3, 2007.

NOIRET, Serge. Historia digital y historia pública. In: BRESCIANO, Juan Andrés; GIL, Tiago (Comp.). La historiografía ante el giro digital: reflexiones teóricas y prácticas metodo-lógicas. Montevideo: Ediciones Cruz del Sur, 2015. p. 41-76.

PY, Fábio. Pandemia cristofascista. São Paulo: Recriar, 2020 a.

PY, Fábio. Bolsonaro's Brazilian Christofascism during the Easter period plagued by Covid-19. International Journal of Latin American Religions, v. 4, p.318-334, $2020 b$.

PAULO RICARDO. A igreja e o desarmamento. YouTube, 2011. Acessado: https://padrepauloricardo.org/episodios/a-igreja-e-o-desarmamento.

PAULO RICARDO. Padre Paulo Ricardo se pronuncia sobre o atentado contra Bolsonaro e o vídeo viraliza na web, Youtube, 2018 disponível em: https://www.youtube.com/watch?v=qvNe82soUEE\&list=LLkZHGIl1HFSKQapVFB5 9m6g\&index=1411.

PAULO RICARDO. A imbecialização do país, Youtube, 2012, acessado em: https://www.facebook.com/jairmessias.bolsonaro/videos/padre-paulo-ricardoe-a-imbeciliza\%C3\%A7\%C3\%A3o-de-umana\%C3\%A7\%C3\%A3o/790458087769846/.

PAULO RICARDO. A igreja prostrada diante de um vírus? Youtube, 22 de março de 2020a. 
PAULO RICARDO. Se o Covid-19, e outras pestes, são castigos de Deus? Indagou se seriam castigos de Deus?, Youtube, 1 de abril de 2020b. Disponível em: https://www.youtube.com/watch?v=2kyUxZkFYM0\&t=910s.

PAULO, RICARDO. Pandemia e os quatro cavaleiros do apocalipse, Página Pessoal, 15 de julho de 2020c. Disponível em: https://padrepauloricardo.org/blog/a-pandemia-e-os-quatro-cavaleiros-doapocalipse.

PLEYERS, G. A "Guerra dos Deuses" no Brasil: da teologia da libertação à eleição de Bolsonaro. Educação \& Sociedade, n.41, 2020.

RÉMOND, R. O retorno do político. In: CHAUVEAU, A.; TETARD, P. (Org.). Questões para a história do presente. Bauru: Edusc, 1999.

RICUPERO, B. O conservadorismo difícil. In: FERREIRA, G. N.; BOTELHO, A. (orgs.). Revisão do pensamento conservador: ideias e política no Brasil. São Paulo: Hucitec-FAPESP, 2010, p. 76-94.

ROLLAND, D. Internet e história do tempo presente: estratégias de memória e mitologias políticas. Tempo, n. 16, vol. 8. Rio de Janeiro: UFF, 2004.

ROSANVALLON, P. Le Bon Gouvernement. Paris: Éditions du Seuil, 2015.

ROCHA, J. C. C. O paradoxo do bolsonarismo e a tragédia brasileira. Folha de São Paulo, 2021.

SCHMITT, C. Théologie politique. Paris: Gallimard, 1988.

SEEGER, Anthony. Uma história de dois arquivos: aquisição, preservação, digitalização e divulgação de acervos audiovisuais. Revista do Instituto de Estudos Brasileiros, n. 48, 2009, p. 31-52.

SILVEIRA, E. J. S. Padres conservadores em armas: o discurso público da guerra cultural entre católicos. REFLEXÃO, v. 43, p.289-309, 2019.

SOLLE, Dorothee. Beyond Mere Obedience: Reflections on a Christian Ethic for the Future, Minneapolis: Augsburg Publishing House, 1970.

SOLLE, Dorothee. Against the Wind: Memoir of a Radical Christian. Minneapolis, Minnesota: Fortress Press, 1999.

SOSSAI, Fernando; MENDES, Geovana. Tempo tecnológico: uma análise de narrativas orais sobre o uso das tecnologias digitais em escolas públicas de Santa Catarina, História Oral, v.19, n.1, 2016.

TAMAYO, Juan José. La internacional del ódio. Barcelona: Icaria, 2020. 
TEIXEIRA DA SILA, F. C. Máscara, Máscaras: Pandemia e Homossexualidade na Novilíngua do Bolsonarismo. Cadernos do Tempo Presente, v. 11, p.1-11, 2020.

TEIXEIRA DA SILA, F. C. Novas tensões Geopolíticas hoje. Cadernos de Estudos Estratégicos, p.29-49, 2019.

TVBRASILGOV. Celebração de Pascoa no Palácio da Alvorada. Youtube.

Disponível em: https://www.youtube.com/watch?v=yoULwu1diHw. Acessado em 02 de junho de 2020.

WEBER, M. A ciência como vocação. São Paulo: Cultix, 1998.

ZEFERINO, J.; ANDRADE, R. A tradução fundamentalista: equivalências hermenêuticas entre teologias exclusivistas e modelos democráticos. Horizonte - Revista de Estudos de Teologia e Ciências da Religião, v.18, n.57, p.1050-169, 2020. 